Article

\title{
Energy-Saving Analysis of Solar Heating System with PCM Storage Tank
}

\author{
Juan Zhao ${ }^{1}$, Yasheng Ji ${ }^{1}$, Yanping Yuan ${ }^{1, *}$, Zhaoli Zhang ${ }^{1}$ and Jun Lu ${ }^{2}$ \\ 1 School of Mechanical Engineering, Southwest Jiaotong University, Chengdu 610031, China; \\ juanzhao1220@163.com (J.Z.); jiyasheng@my.swjtu.edu.cn (Y.J.); zhangzl_sju@163.com (Z.Z.) \\ 2 School of Urban Construction \& Environment Engineering, Chongqing University, \\ Chongqing 400045, China; lujun66@vip.sina.com \\ * Correspondence: ypyuan@home.swjtu.edu.cn; Tel./Fax: +86-028-8763-4937
}

Received: 18 November 2017; Accepted: 15 January 2018; Published: 19 January 2018

\begin{abstract}
A solar heating system (SHS) with a phase change material (PCM) thermal storage tank is proposed with the view that traditional heat water storage tanks present several problems including large space requirements, significant heat loss and unstable system performance. An entire heating season (November-March) is selected as the research period on the basis of numerical models of the SHS-PCM. In addition, taking a public building in Lhasa as the object, the heating conditions, contribution rate of solar energy, and overall energy-saving capability provided by the heating system are analyzed under different PCM storage tanks and different terminal forms. The results show that an SHS with a PCM tank provides a 34\% increase in energy saving capability compared to an ordinary water tank heating system. It is suggested that the design selection parameters of the PCM storage tank should specify a daily heat storage capacity that satisfies $70 \sim 80 \%$ of the entire heating season. A floor radiant system with supply/return water temperatures of $40 / 35^{\circ} \mathrm{C}$ provides the optimal operation and the largest energy saving capability.
\end{abstract}

Keywords: flat-plate solar thermal collector; PCM storage tank; terminal forms; energy-saving analysis

\section{Introduction}

Building heating with solar energy significantly reduces the use of non-renewable energy sources and relieves air pollution stress; these outcomes have obvious environmental and economic benefits. However, traditional solar heating systems present several issues, including intermittent operation, weather instability, and low energy density, etc. While traditional heat water storage tanks indicate problems, such as large space requirements and significant heat loss due to the sensible form of heat storage. Moreover, system performance is unstable owing to significant temperature fluctuation [1]. Extensive research has been performed on new types of solar thermal collectors [2-4] and phase change material (PCM) which together appear to be a promising solution as they possess high latent heat density and isothermal phase change characteristics [5,6]. Adding PCM into the heat storage unit cannot only reduce the volume but also allow heat to be stored and released at a nearly constant temperature, avoiding the shortcomings of traditional water tanks [7]. In order to address the issues of solar energy instability and heat storage insufficiency, an auxiliary heat source (AHS) is typically added into solar heating systems. Greater attention has been paid to the combination of solar energy and AHS, owing to its inconspicuous environmental benefit and operating cost; Moreover, it has become an important research topic.

Extensive works have been carried out to explore the application of PCMs in solar thermal energy [8], such as solar power plants [9,10], solar air heaters [11], solar water heaters [12-14], solar desalination facilities, solar cookers, solar air conditioning [15,16], etc. Many forms of PCM 
storage units for use of building heating systems have been proposed by numerous scholars [17]. However, many issues still need to be overcome before they are being widely used. Belmonte et al. [18] presents a simple method for modeling the performance of the thermal energy storage (TES) system that contains PCMs. The developed approach is similar in the concept to the bypass factor method, which is widely used in the air conditioning applications to estimate the outlet air conditions from a coil. The method can be implemented in whole-building simulation tools such as TRNSYS. An experimental investigation of a latent thermal energy storage (LTES) tank with a composite of paraffin was carried out by Zhang et al. [19]. PCMs and water temperature distribution were analyzed during the charging and discharging processes. A tube-in-tank LTES unit using paraffin as a PCM was built by Meng et al. [20]. The thermal performance of the LTES unit with the composite PCM was investigated experimentally, and a 3D numerical model was established to study the heat transfer mechanisms of the LTES unit. It was concluded that the LTES unit with the composite PCM showed good heat transfer performance. In addition, increasing the inlet flow velocity of the HTF and increasing the temperature difference between the HTF and PCM could enhance heat transfer and benefit thermal energy utilization. Lu et al. [21] proposed a water storage tank containing two types of PCMs with different melting points. Results show that the presence of PCMs with different melting points can significantly shorten heat storage time. An increase in PCM content in the tank leads to an evident increase in heat release.

A performance comparison between SHS-PCM and SHS-without PCM has been put forward. Kumar et al. [22] analyzed the effect of adding PCM encapsulated in spherical capsules at the top of a hot water storage tank for stratification enhancements during the charging process. The temperature profile along the height of the storage tank was analyzed for TES systems with and without PCM capsules. The experimental results showed that the sensible-heat thermal energy storage system required less overall charging time than the system with PCM capsules. However, this difference in charging time was reduced with an increase in HTF inlet temperature. Talmatsky et al. [23] constructed a model to describe a heat storage tank with and without PCM, a collector, a pump, a controller, and an auxiliary heater. The results of all simulation scenarios indicated that the use of PCM in the storage tank does not yield a significant increase in the energy provided to the end user. The main reason for this undesirable effect was found to be the increased nighttime heat losses due to reheating the water by the PCM. Regarding SHS-PCM optimization, Najafian et al. [24] described how implementing PCM in a standard domestic hot water tank affects energy consumption and the discharge period, and suggested a tank optimization method that centers on their discharge time. Haillot et al. [25] placed PCM in the heat transfer fluid solar loop of an SDHW system, then studied the results under different weather conditions and system parameters. The parametric study highlighted a significant increase in system efficiency resulting from the PCM. Subsequently, a genetic algorithm allowed an optimized system configuration to be proposed. Padovan et al. [26] studied a simple SDHW that features a plane solar thermal collector, a boiler, and a PCM-enhanced storage tank. The PCM-enhanced tank was optimized using mono- and multi-objective genetic algorithms. At present, the dynamic performance of solar heating systems with PCM was mainly in experimental researches. The performance of a combined solar-heat pump system with energy storage in encapsulated PCM packing for residential heating was investigated both experimentally and theoretically at the Karadeniz Technical University by Kaygusuz et al. [27]. Zhang et al. [28] proposed a new solar energy-phase change storage-floor radiant heating system to provide a comfortable indoor environment in winter, which was installed in an office building in Urumqi, China. The results showed that it could provide a $30 \%$ increase in utilization of solar energy compared to a traditional solar heating system (SHS).

A SHS-PCM should synthetically consider the energy efficiency over the entire heating cycle. Previous studies considered only a few days or hours and only particular operating conditions in their experimental investigations, and there is no available study that employs mathematical simulation or experiments to evaluate the performance of the entire system over an extended period. 
Based on the numerical models of a solar heating system coupled with PCM thermal storage [29], the entire heating season is chosen as the research period, and a public building in Lhasa is taking as the object. The heating conditions, contribution rate of solar energy, and the overall energy saving capability provided by the heating system were analyzed from the following two aspects: daily heat supply with AHS, and the proportion of heat supplied by three sources (AHS, direct heating of flat-plate solar thermal collectors (FSTCs), and PCM storage tank). This analysis provides theoretical support for the optimization and application of the system.

\section{Structures and Operation Modes of SHS-PCM}

\subsection{Structures}

The system under investigation is shown in Figure 1 and represents a typical solar heating system with PCM storage tank (SHS-PCM). It is mainly composed of a solar collecting system (SCS), a phase change thermal storage system (PCTSS), and an indoor heating system (IHS). As the main thermal source, SCS is composed of FSTCs, a plate heat exchanger, pump 1, valves, pipelines, etc. As the heating supply source, PCTSS is composed of a PCM storage tank, an AHS, a plate heat exchanger, pump 2, valves, pipelines, etc. The hourly heating load of the IHS is calculated by DeST software (Tsinghua University, Beijing, China), to determine a suitable supply water temperature and backwater temperature for the form of indoor heat exchangers.

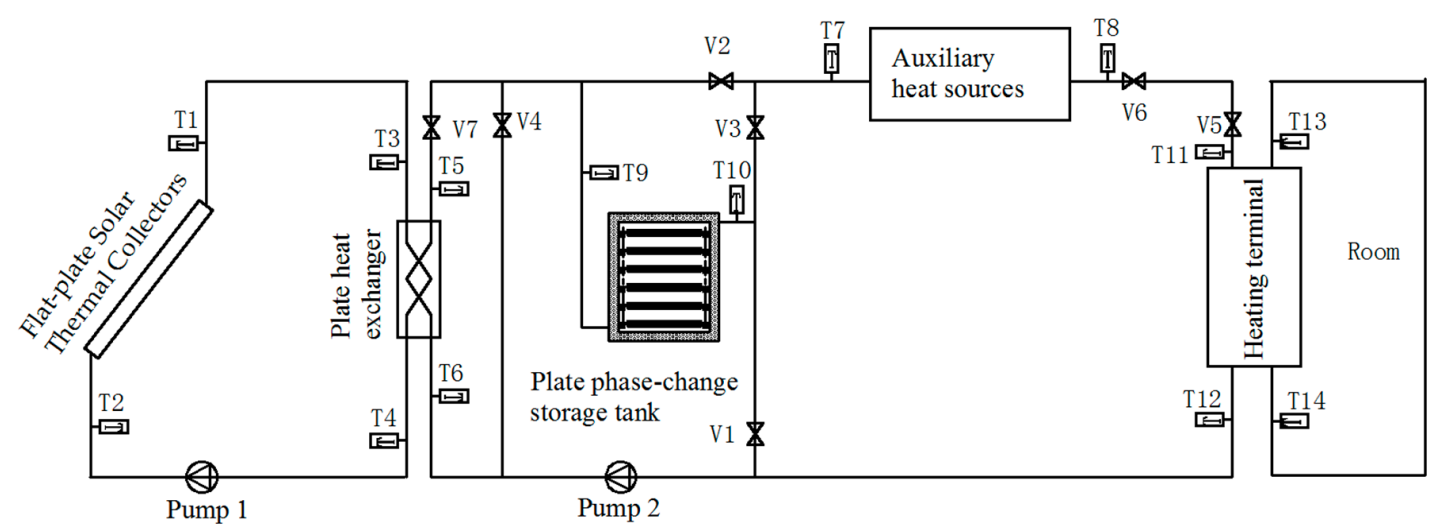

Figure 1. Schematic diagram of the solar heating system-phase change material (SHS-PCM).

Figure 2 shows a schematic of the PCM storage tank. The PCM is packed into flat metal boxes, which are stacked in layers in the phase change heat storage tank.

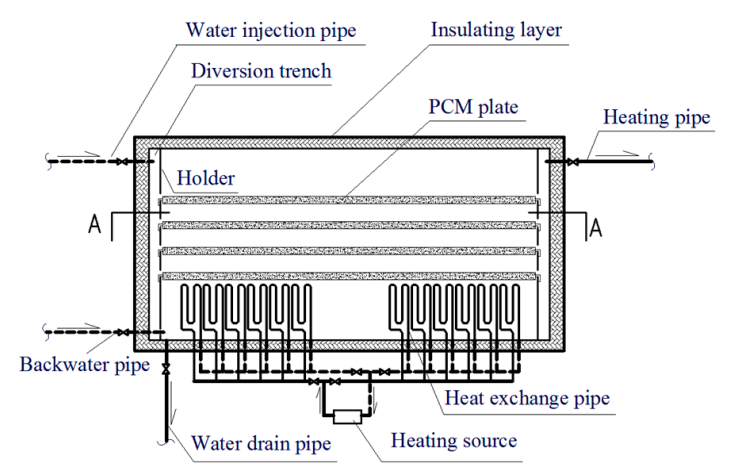

(a)

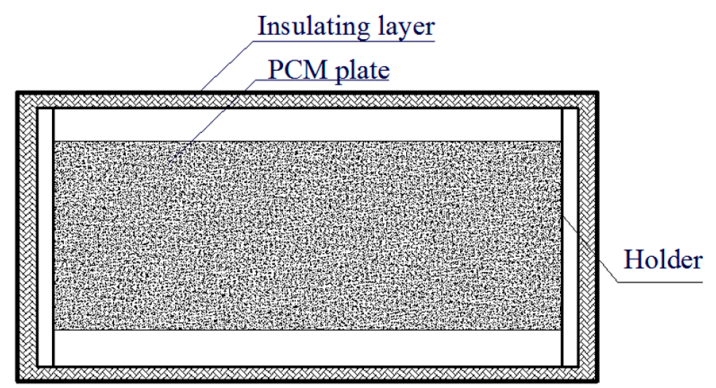

(b)

Figure 2. (a) Front view of the phase change material (PCM) storage tank; (b) A-A cross section of the PCM storage tank. 


\subsection{Operation Modes}

Considering the operational stability and the manageability of the control system, the following seven heating operation modes are proposed for the SHS-PCM:

Mode 1: Natural cooling

Mode 2: Reserve the heat absorbed by the solar collection system in the PCM storage tank when no indoor heating is required.

Mode 3: Directly supply the indoor heating demand using the solar collection system.

Mode 4: Supply the heat absorbed by the solar collection system to the rooms, and store excess absorbed heat in the PCM storage tank.

Mode 5: Supply the heat stored in the PCM storage tank to the rooms.

Mode 6: Supply the room heating demands using the PCM storage tank and AHS simultaneously.

Mode 7: Supply the room heating demands using only the AHS.

When there is shortage of solar radiation and without the terminal load, all the components will be suspended and naturally cooled (Mode 1). When the solar radiation is available, the FSTCs will collect solar radiation and use it to heat the contained water. If the water reaches the phase-transition temperature of the PCM, the PCM storage tank begins to store the heat absorbed by the water (Mode 2). If the water is heated to the indoor heat supply temperature, the heat can be directly supplied to the rooms (Mode 3). If excess heat is available beyond that demanded by the rooms, it can be stored in the PCM storage tank (Mode 4). If there is no useful solar radiation to collect, the solar collection system would be temporarily out of service and the room heating demands would first be supplied by the PCM storage tank (Mode 5). However, if the PCM storage tank contains insufficient thermal energy to meet the heating demands of the room, it would be assisted by the AHS (Mode 6). If the PCTSS and SCS are both incapable of contributing to the indoor heating requirements, the AHS would operate alone (Mode 7).

With reference to the valve and temperature numbering in Figure 1, the system operating modes and control parameters are listed in Table 1.

Table 1. Operating modes and control parameters of the SHS-PCM. FSTCs: flat-plate solar thermal collectors; AHS: auxiliary heat source.

\begin{tabular}{|c|c|c|c|c|c|}
\hline Mode & Detail & $\begin{array}{c}\text { Flat-Plate Solar } \\
\text { Thermal Collectors } \\
\text { (FSTCs) }\end{array}$ & $\begin{array}{c}\text { PCM } \\
\text { Storage } \\
\text { Tank }\end{array}$ & $\begin{array}{l}\text { Auxiliary } \\
\text { Heat Source } \\
\text { (AHS) }\end{array}$ & Operation \\
\hline Mode 1 & Natural cooling & Off & Off & Off & All valves closed \\
\hline Mode 2 & $\begin{array}{l}\text { FSTCs for PCM } \\
\text { storage tank }\end{array}$ & On & On & Off & $\begin{array}{l}\text { Valves V7 and V1 opened; } \\
\text { Pumps } 1 \text { and } 2 \text { on }\end{array}$ \\
\hline Mode 3 & FSTCs for indoor heating & On & Off & Off & $\begin{array}{l}\text { Valves V7, V2, V6, and V5 } \\
\text { opened; Pumps } 1 \text { and } 2 \text { on }\end{array}$ \\
\hline Mode 4 & $\begin{array}{l}\text { FSTCs for PCM storage } \\
\text { tank and indoor heating }\end{array}$ & On & On & Off & $\begin{array}{c}\text { Valves V7, V1, V2. V6, and V5 } \\
\text { opened; Pumps } 1 \text { and } 2 \text { on }\end{array}$ \\
\hline Mode 5 & $\begin{array}{l}\text { PCM storage tank for } \\
\text { indoor heating }\end{array}$ & Off & On & Off & $\begin{array}{l}\text { Valves V3, V6, V5, and V4 } \\
\text { opened; Pump } 2 \text { on }\end{array}$ \\
\hline Mode 6 & $\begin{array}{l}\text { PCM storage tank and } \\
\text { AHS for indoor heating }\end{array}$ & Off & On & On & $\begin{array}{l}\text { Valves V3, V6, V5, V4 opened; } \\
\text { Pump } 2 \text { on; AHS on }\end{array}$ \\
\hline Mode 7 & AHS for indoor heating & Off & Off & On & $\begin{array}{l}\text { Valves V6, V5, V4, and V2 } \\
\text { opened; Pump } 2 \text { on; AHS on }\end{array}$ \\
\hline
\end{tabular}

\section{Dynamic Simulation Model of System}

The dynamic simulation model of the system can be simplified into the four sub-models shown in Figure 3, based on the physical model of the SHS-PCM. The dynamic simulation model of the system can be established by solving the problem based on the physical meaning of each sub-model, the equation of the heat transfer process, and the operation control strategy of the system [29]. 


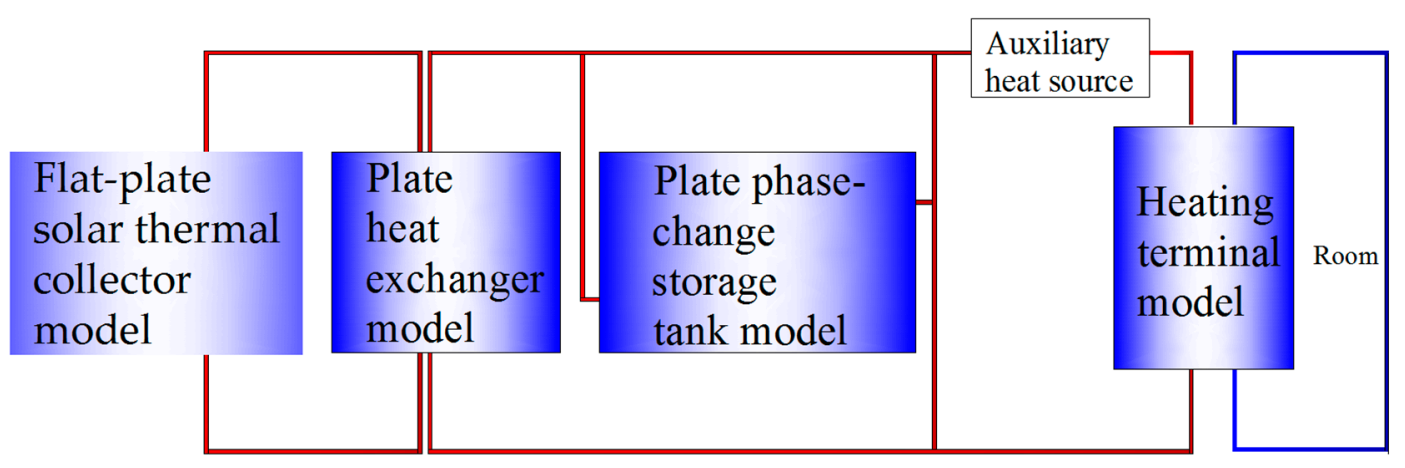

Figure 3. Simplified dynamic simulation model of SHS-PCM.

\subsection{Model of the Flat-Plate Solar Thermal Collector}

The heat collection process includes heat transfer between the glass cover plate and the environment, heat transfer between the glass cover plate and the heat absorption plate, heat transfer between the heat absorption plate and the bottom plate, and heat transfer between the heat absorption plate and the side panels. The corresponding heat transfer coefficient can be calculated by analyzing each heat transfer process. Therefore, the heat efficiency, the efficiency factor, and the heat transfer factor of the collector can be obtained using the energy conservation equation. A schematic illustration of the energy conservation of a FSTC is shown in Figure 4.

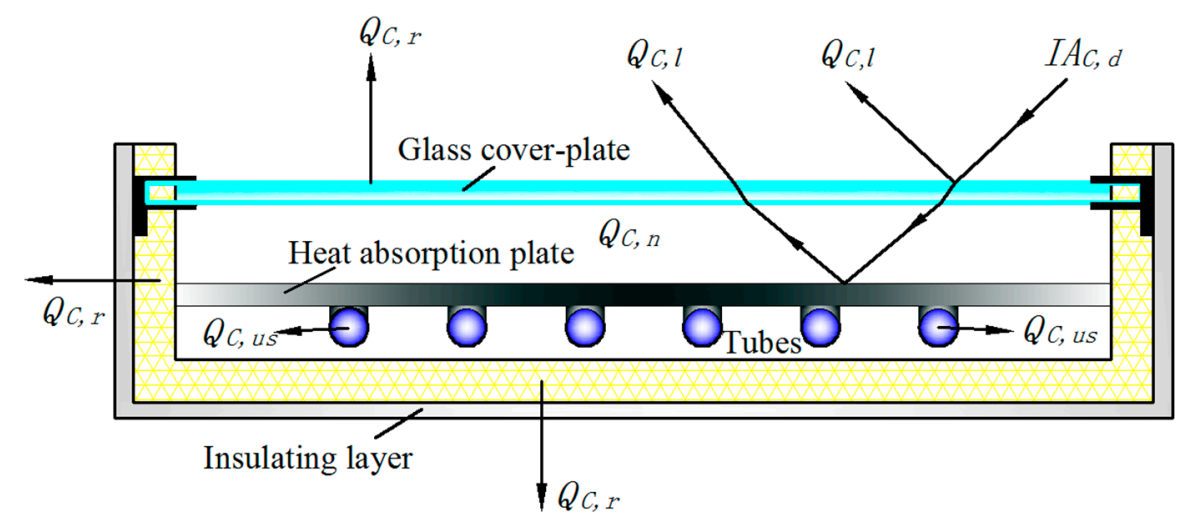

Figure 4. Schematic of the energy conservation of a FSTC.

According to the conservation of energy, the solar radiation energy per unit time projected to the glass cover is equal to the sum of the light loss $Q_{C, l}$, heat loss $Q_{C, r}$, internal energy increment of the collector $Q_{\mathrm{C}, n}$, and useful energy $Q_{\mathrm{C}, u s}$ obtained by the working substance, as expressed in Equation (1).

$$
I A_{C, d}=Q_{C, l}+Q_{C, r}+Q_{C, u s}+Q_{C, n}
$$

\subsection{Model of the PCM Storage Tank}

During the transfer of heat between the fluid and the phase change heat storage unit at any given time, the lower part of the PCM is solidified /melted after the release/absorption of latent heat. The lower solid/liquid phase region and the upper liquid/solid phase region are formed next to the boundary of the phase transition interface. The half-layer PCM plate and fluid channel are used to investigate the heat transfer of the PCM storage tank. As indicated in Figure 5, the upper and lower boundaries of the PCM units can be considered as adiabatic surfaces. This is because of the symmetry of the flat phase change thermal storage unit model. 


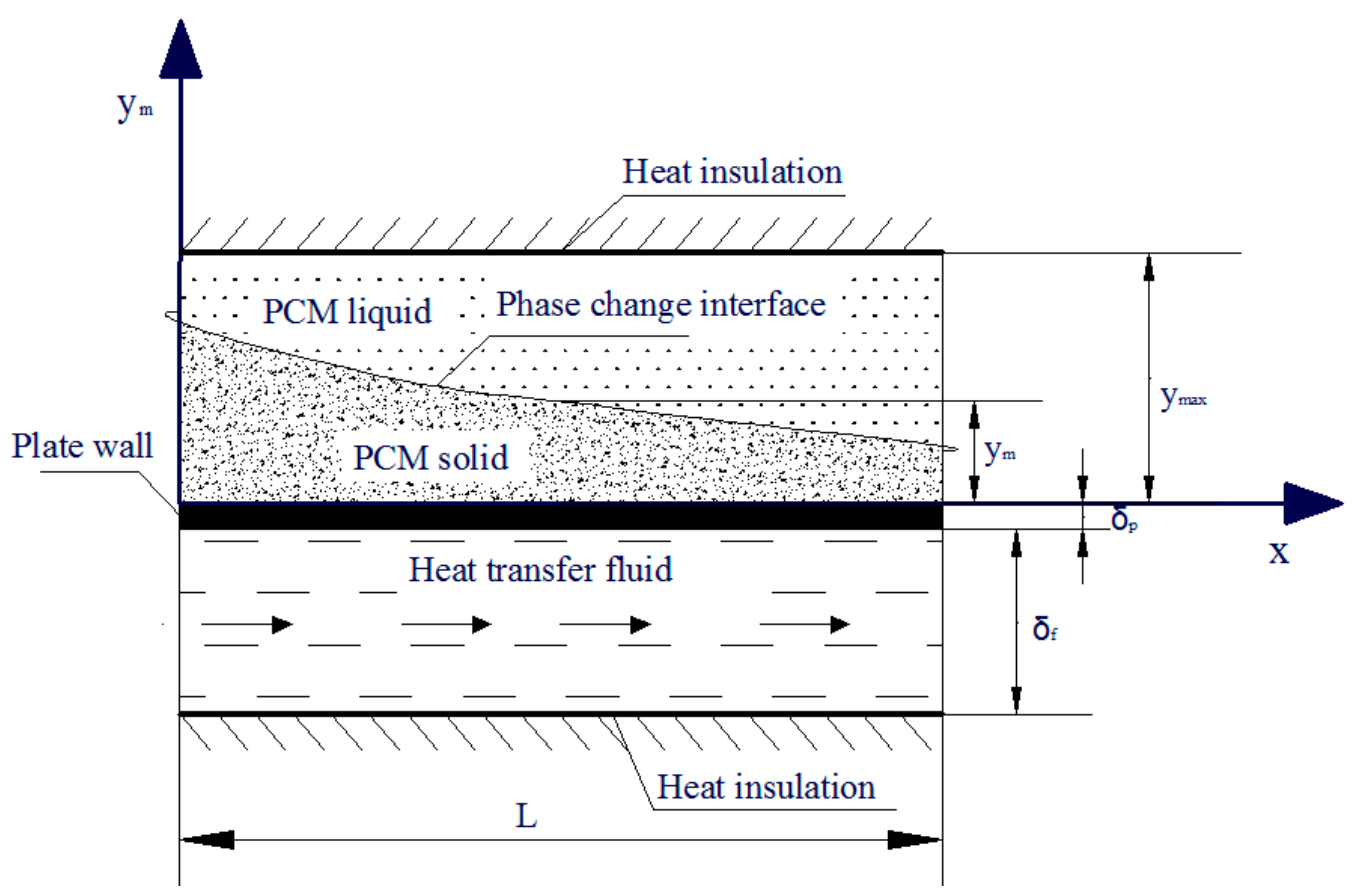

Figure 5. Mathematical model of the phase change thermal storage unit.

The following equations apply:

$$
\text { PCM : } \quad H_{m} \times \rho_{m} \times \frac{\partial A_{m}(x, t)}{\partial t}=K_{f-m} \times p \times\left[T_{f}(x, t)-T_{m}\right]
$$

In Equation (2), $A_{m}$ is the cross-sectional area of the transformed PCM, $K_{f-m}$ is the heat transfer coefficient, $p$ is the wetted perimeter, $T_{f}$ is the fluid temperature, and $T_{m}$ is the phase transition temperature of the PCM.

$$
\begin{gathered}
\text { Heat transfer fluid : } m_{f} \times C_{p, f} \times \frac{\partial T_{f}(x, t)}{\partial x}=-K_{f-m} \times p \times\left[T_{f}(x, t)-T_{m}\right] \\
K_{f-m}=h_{f} \times \beta \\
\beta(x, t)=\frac{R_{f}}{R_{f}+R_{p}+R_{m}(x, t)}
\end{gathered}
$$

In Equation (5), $R_{f}, R_{p}$, and $R_{m}$ are the convective thermal resistance of the fluid, conductive thermal resistance of the package plate wall, and conductive thermal resistance of the transformed PCM, respectively.

$$
R_{f}=1 / h_{f}, R_{m}=y_{m} / K_{m}, R_{p}=\delta_{p} / K_{p}
$$

Initial condition: $A_{m}(x, t=0)=\mathrm{A}_{m, 0}(x), T_{f}(x, t=0)=T_{f, 0}$.

Boundary condition: $T_{f}(x=0, t)=T_{f, i n}(t)$.

\subsection{Model of Plate Heat Exchanger}

The plate heat exchanger is a heat exchange component between the solar thermal collectors and the PCM storage tank. The relationship between the inlet and outlet parameters of the plate heat exchanger is determined by the principle of heat balance with no heat loss.

$$
Q_{h}=K_{h} \times A_{h} \times \Delta T_{h t}=C_{p, w 1} \times m_{h, 1} \times\left(T_{h 1, i n}-T_{h 1, o}\right)=C_{p, w 2} \times m_{h, 2} \times\left(T_{h 2, o}-T_{h 1, i n}\right)
$$




$$
\Delta T_{h t}=\frac{T_{h 1, i n}+T_{h 1, o}}{2}-\frac{T_{h 2, o}+T_{h 2, i n}}{2}
$$

where $Q_{h}$ is the heat quantity of the plate heat exchanger $(\mathrm{W}), K_{h}$ is the heat transfer coefficient $\left(\mathrm{W} /\left(\mathrm{m}^{2} \cdot{ }^{\circ} \mathrm{C}\right)\right), A_{h}$ is the area of the plate heat exchanger $\left(\mathrm{m}^{2}\right)$, and $\Delta T_{h t}$ is the logarithmic mean temperature difference between both sides of the heat exchanger $\left({ }^{\circ} \mathrm{C}\right)$, given by Equation $(7)$.

The mathematical heat transfer model of the FSTC, PCM storage tank, and plate heat exchanger has been presented above. In this study, the load on the terminal forms is calculated using DeST, while the dynamic coupled heat transfer model of the system is developed with respect to the operation modes.

\section{Design Parameter Settings and Methodologies of the Object}

This study uses a multi-story public building in Lhasa as the object, as shown in Figure 6. The building has five floors, each floor is $3.9 \mathrm{~m}$ in height, and the heating area is $3778.87 \mathrm{~m}^{2}$.

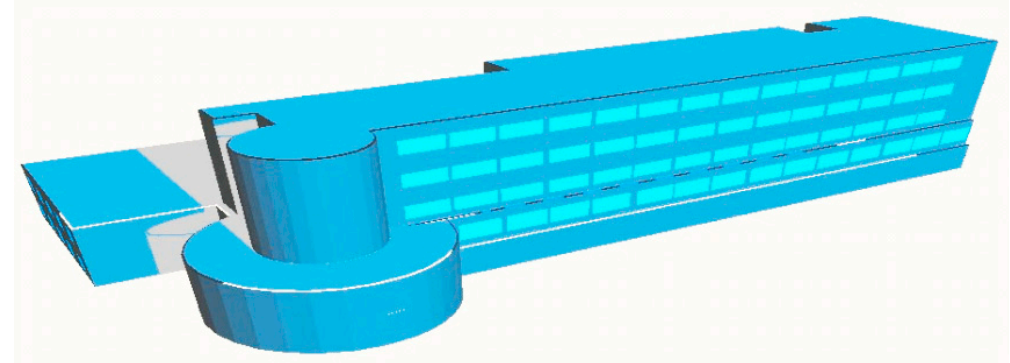

Figure 6. DeST model of the public building.

The function of the PCM storage tank is to store the heat of solar radiation, and release heat to meet indoor heating needs when no solar radiation is available. Therefore, the amount of PCM is determined by the difference between the heat collection efficiency and the indoor heating load. Figure 7 gives the hourly graph of the useful energy of the collector and the building heat load for December 1, while the building uses a fan coil as a terminal.

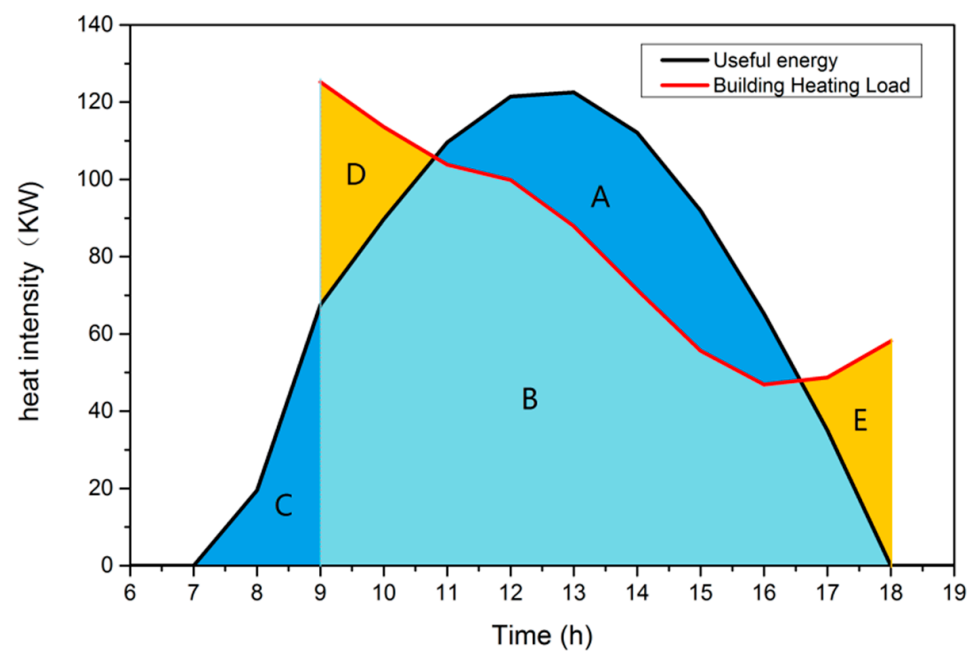

Figure 7. Hourly graph of useful energy of collector and building heat load.

$\mathrm{A}+\mathrm{B}+\mathrm{C}$ is the useful energy collected by FSTCs per day and B $+\mathrm{D}+\mathrm{E}$ is the total indoor heat load in the diagram. According to the diagram, the heat required for PCMs is the excess solar radiation in the $\mathrm{A}+\mathrm{C}$ region. A cumulative calculation of the daily heat storage in the heating season is shown in Figure 8. 


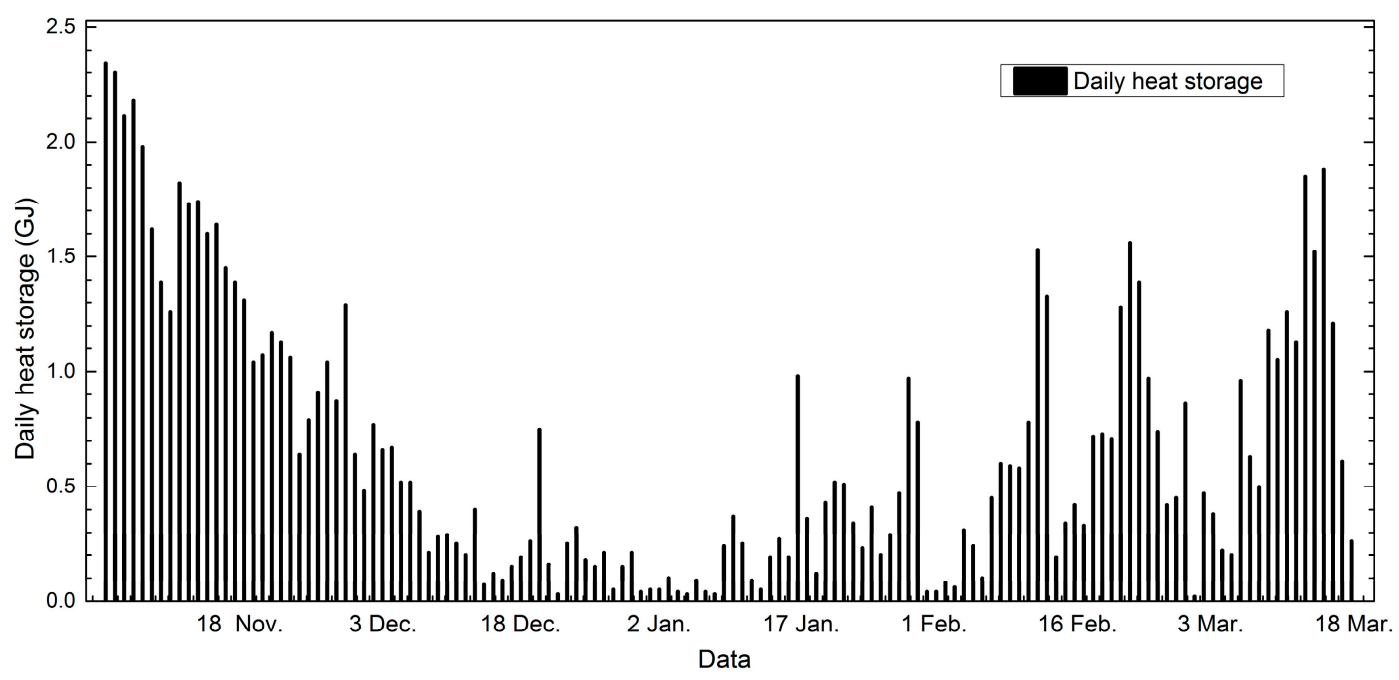

Figure 8. Daily heat storage in the heating season.

Figure 8 is the daily heat storage capacity of the public building with fan coil as terminals, with a maximum value of 3.27 GJ. According to Equation (8), the amount of PCM is calculated.

$$
Q_{m}=M_{m} \times\left[C_{p f} \times\left(T_{m, 2}-T_{m}\right)+C_{p s} \times\left(T_{m}-T_{m, 1}\right)+H_{m}\right]
$$

where $Q_{m}$ - heat quantity of PCM, kJ;

$M_{m}$-Weight of PCM, kg;

$C_{p f}$-Specific heat of liquid PCM at constant pressure, $\mathrm{kJ}\left(\mathrm{kg}{ }^{\circ} \mathrm{C}\right)^{-1}$;

$C_{p s}-$ Specific heat of solid PCM at constant pressure, $\mathrm{kJ}\left(\mathrm{kg}^{\circ} \mathrm{C}\right)^{-1}$;

$T_{m, 1}$ - Low temperature of solid PCM endothermic, ${ }^{\circ} \mathrm{C}$;

$T_{m, 2}$ - High temperature of liquid PCM endothermic, ${ }^{\circ} \mathrm{C}$;

$T_{m}$-Phase-transition temperature, ${ }^{\circ} \mathrm{C}$;

$\mathrm{H}_{m}$-Latent heat, $\mathrm{kJ} / \mathrm{kg}$.

The volume of the PCM storage tank can be calculated according to Equation (9) after the amount of PCM is determined.

$$
V_{p h}=V_{m} / \varepsilon_{v}
$$

In which: $V_{p h}$-Volume of water tank, $\mathrm{m}^{3}$;

$V_{m}$-Volume of PCM, $\mathrm{m}^{3}$;

$\varepsilon_{v}$-Volume fraction

Floor radiation, fan coil and radiator can be chosen as the heating terminals, and the operating temperatures are selected according to "Design Code for Heating Ventilation and Air Conditioning of Civil Buildings (GB50736-2012)" [30]: (1) 35 45 ${ }^{\circ} \mathrm{C}$ is the suitable range of supply heating medium temperature for heating system with hot water floor radiations, which should not be above $60^{\circ} \mathrm{C}$. The difference between supply and return water temperature should not be greater than $10^{\circ} \mathrm{C}$, and not be less than $5^{\circ} \mathrm{C}$. (2) $40 \sim 65^{\circ} \mathrm{C}$ is the suitable range of supply heating medium temperature for heating system with fan coils, and the difference between supply and return water temperature is within $4.2 \sim 15{ }^{\circ} \mathrm{C}$. (3) $75{ }^{\circ} \mathrm{C} / 50{ }^{\circ} \mathrm{C}$ is the suitable supply/return heating medium temperature for heating system with radiators. The supply heating medium temperature should not be above $85^{\circ} \mathrm{C}$ and the difference between supply and return heating medium temperature should not less than $20^{\circ} \mathrm{C}$.

When using the floor radiation and fan coil as the heating terminals, flat-plate solar thermal collector is the best choice in Lhasa for its characteristics of low cost and not easy to damage. When using the radiator, the concentrating solar collector with heat conducting oil would be better. 
Table 2. Parameter calculation table of the SHS-PCM for the public building.

\begin{tabular}{|c|c|c|c|c|c|c|c|}
\hline \multirow{2}{*}{\multicolumn{3}{|c|}{ Architecture Type: Public Buildings }} & \multicolumn{2}{|c|}{ Floor Radiation } & \multicolumn{2}{|c|}{ Fan Coil } & \multirow{3}{*}{$\begin{array}{c}\text { Radiator } \\
\text { Condition } \mathbf{5} \\
70 / 45\end{array}$} \\
\hline & & & \multirow{2}{*}{$\begin{array}{c}\text { Condition } 1 \\
40 / 35\end{array}$} & \multirow{2}{*}{$\begin{array}{c}\text { Condition } 2 \\
40 / 30\end{array}$} & \multirow{2}{*}{$\begin{array}{c}\text { Condition } 3 \\
45 / 40\end{array}$} & \multirow{2}{*}{$\begin{array}{c}\text { Condition } 4 \\
45 / 35\end{array}$} & \\
\hline $\begin{array}{l}\text { Supply and return temperature of } \\
\text { fluid } 3\end{array}$ & $T_{e, i n} / T_{e, t}$ & ${ }^{\circ} \mathrm{C}$ & & & & & \\
\hline $\begin{array}{l}\text { Design temperature difference of } \\
\text { plate heat exchanger }\end{array}$ & - & ${ }^{\circ} \mathrm{C}$ & 5 & 10 & 5 & 10 & 25 \\
\hline $\begin{array}{l}\text { Supply and return temperature of } \\
\text { fluid } 1\end{array}$ & $T_{C, i n} / T_{C}$ & ${ }^{\circ} \mathrm{C}$ & $45 / 40$ & $50 / 40$ & $50 / 45$ & $55 / 45$ & $120 / 70$ \\
\hline \multicolumn{3}{|c|}{ Collector type } & FSTC & FSTC & FSTC & FSTC & Concentrating solar collector \\
\hline \multicolumn{3}{|c|}{ Heat transfer fluid of the collector side } & water-glycol & water-glycol & water-glycol & water-glycol & heat conducting oil \\
\hline Heat transfer coefficient & $K_{h}$ & $\mathrm{~W} /\left(\mathrm{m}^{2}{ }^{\circ} \mathrm{C}\right)$ & 4124 & 4631 & 4124 & 4631 & 1996 \\
\hline Area of the plate heat exchanger & $A_{h}$ & $\mathrm{~m}^{2}$ & 15.5 & 6.4 & 15 & 6.4 & 5.2 \\
\hline Area of single plate heat collector & $A_{C}$ & $\mathrm{~m}^{2}$ & 2.23 & 2.23 & 2.23 & 2.23 & - \\
\hline Number of heat collectors & $N_{C}$ & - & 88 & 88 & 88 & 88 & 88 \\
\hline Total flow of fluid 1 & $m_{f 1}$ & $\mathrm{~kg} / \mathrm{s}$ & 10.85 & 5.3 & 10.55 & 5.16 & 1.39 \\
\hline Total flow of fluid 2 & $m_{f 2}$ & $\mathrm{~kg} / \mathrm{s}$ & 9.45 & 4.62 & 9.26 & 4.53 & 1.54 \\
\hline Specific heat of fluid 2 & $C_{p f 2}$ & $\mathrm{~J} /(\mathrm{kg} \cdot \mathrm{K})$ & 4174 & 4174 & 4174 & 4174 & 4179 \\
\hline Solution density of fluid 1 & $\rho_{f 1}$ & $\mathrm{~kg} / \mathrm{m}^{3}$ & 1042 & 1042 & 1037 & 1037 & 850 \\
\hline Solution density of fluid 2 & $\rho_{f 2}$ & $\mathrm{~kg} / \mathrm{m}^{3}$ & 992.2 & 992.2 & 990 & 990 & 983 \\
\hline Volume of PCM storage tank & $V_{h p}$ & $\mathrm{~m}^{3}$ & $3 \times 2.5 \times 1.9$ & $3 \times 2.5 \times 1.9$ & $3 \times 2.5 \times 2$ & $3 \times 2.5 \times 2$ & $3 \times 2.5 \times 1.6$ \\
\hline \multicolumn{3}{|c|}{ PCM materials } & Lauric acid & Lauric acid & paraffin & paraffin & hydrated salts \\
\hline Phase-transition temperature & $T_{m}$ & ${ }^{\circ} \mathrm{C}$ & 43 & 43 & 47 & 47 & 72 \\
\hline Volume of PCM plate & $V_{p p}$ & $\underset{\mathrm{m}}{\mathrm{m} \times \mathrm{m} \times}$ & $3 \times 2.5 \times 0.08$ & $3 \times 2.5 \times 0.08$ & $3 \times 2.5 \times 0.08$ & $3 \times 2.5 \times 0.08$ & $3 \times 2.5 \times 0.08$ \\
\hline Number of PCM plates & $N_{p p}$ & - & 14 & 14 & 14 & 14 & 12 \\
\hline AHS & & & $\begin{array}{l}\text { air-cooled heat } \\
\text { pump }\end{array}$ & $\begin{array}{l}\text { air-cooled heat } \\
\text { pump }\end{array}$ & $\begin{array}{l}\text { air-cooled heat } \\
\text { pump }\end{array}$ & $\begin{array}{l}\text { air-cooled heat } \\
\text { pump }\end{array}$ & Gas fired boiler \\
\hline
\end{tabular}


The main design parameters are shown in Table 2, according to different selection methods. The heating period ran from November 4th to March 19th of the following year (a total of 136 days), and the meteorological parameters and solar radiation intensity are selected from typical meteorological parameters in Lhasa, China. The specifications and quantities of solar thermal collectors, plate heat exchanger and AHS are calculated according to "Technical code for solar heating system (GB 50495-2009) [31]".

The methodologies are as follows: (1) Design the solar heating system with PCM storage tank based on select typical buildings firstly. Dynamic simulation models of SHS-PCM and the control strategy are established secondly. Then the design parameters are inputted in the simulation models to get the system operating parameters at each moment of the whole heating season; (2) Different design schemes are set up and simulated respectively, and the most energy saving design scheme is obtained by comparing the running parameters.

\section{Results and Discussion}

The heat of the heating system is supplied by the AHS, the direct heating of the FSTCs, and the heat storage tank. The heat of the FSTCs and the storage tank comes from solar energy. The ratio of these two types of heat is defined as the energy saving rate. Therefore, the state of the heating system can be quantitatively analyzed by using the daily heating load of the building and the daily heat supplied by the AHS. The ratio of contribution of solar energy to the heating system and the general energy saving status can be determined according to the proportion of heat supplied by the three sources during the entire heating season.

The following systems are compared and analyzed from the perspective of quantization, and by using the ratio that reflects (1) the daily heat supplied by AHS and (2) the proportion of heat supplied by the three sources.

(1) A coupled model of an ordinary water tank was established to analyze the operating conditions of a common water tank and a PCM storage tank combined with SHS, in order to explore how the ordinary water tank and the PCM storage tank contributed to the solar heating system.

(2) Operating conditions with different sizes of heat water storage tanks are compared in order to optimize the selection of the heat water storage tank.

(3) Operating conditions with different terminal forms and different supply and return water temperatures are compared in order to find the best match between the terminal form and the PCM storage tank.

\subsection{Operating Conditions of Different PCM Storage Tanks}

\subsubsection{Operating Conditions Comparison between SHS-PCM and SHS-without PCM}

The reference parameters of the SHS-PCM model are shown in Table 2, Case 5. The SHS-without PCM and SHS-PCM are consistent, except for the tank forms. The design parameter is performed on the basis of the "Technical code for solar heating system (GB 50495-2009) [31]" for ordinary water tanks selection calculation. The PCM storage tank is only considered latent heat storage with the same heat storage capacity. The selection parameters of both tanks are shown in Table 3.

Figure 9 shows a box chart of daily energy delivered by the AHS of SHS-PCM and SHS-without PCM, along with the daily heat consumption of the building during the entire heating season. The data on the left of the box chart show the daily heat supplied by the AHS of SHS-without PCM. The average daily heat supply is $3964 \mathrm{MJ} /$ day, and the distribution of the points is between $0 \sim 14,041 \mathrm{MJ} /$ day. The data in the middle of the box chart show the daily heat supplied by the AHS of SHS-PCM. The average daily heat supply is $2202 \mathrm{MJ} /$ day, and the distribution of the points is between 201 5956 MJ/day. The data on the right of the box chart show daily building energy consumption. The average daily energy consumption is $5225 \mathrm{MJ} /$ day, and the distribution of the points is between 2088 8217 MJ/day. The figure shows that the daily heat supply of SHS-without PCM is occasionally 
even higher than the building heat consumption. This is because of the serious heat dissipation of the ordinary water tank. The AHS supplies not only indoor heating, but also the heat loss of the ordinary water tank.

Table 3. Selection parameters for ordinary water tank and PCM storage tank.

\begin{tabular}{ccccc}
\hline & Nomenclature & Units & Ordinary Water Tank & PCM Storage Tank \\
\hline Heat storage capacity & $Q_{m}$ & $\mathrm{GJ}$ & 0.63 & 0.63 \\
Volume of tank & $V_{h p}$ & $\mathrm{~m}^{3}$ & $3 \times 2.5 \times 4$ & $3 \times 2.5 \times 0.8$ \\
Volume of PCM plate & $V_{p p}$ & $\mathrm{~m}^{3}$ & - & $3 \times 2.5 \times 0.08$ \\
Number of PCM plates & $N_{p p}$ & & - & 6 \\
PCM materials & & & - & paraffin \\
Phase-transition temperature & $T_{m}$ & ${ }^{\circ} \mathrm{C}$ & fan coil & fan coil \\
Terminal form & & & $45 / 40$ & $45 / 40$ \\
\hline Supply and return heating temperature & $T_{e, i n} / T_{e, o}$ & ${ }^{\circ} \mathrm{C}$ & & \\
\hline
\end{tabular}

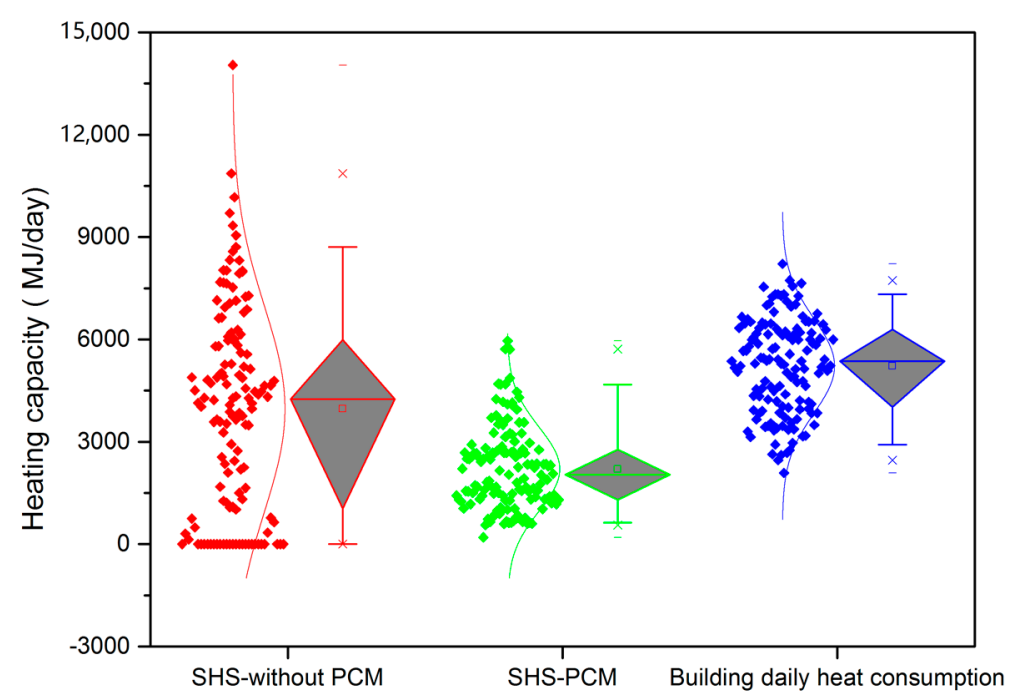

Figure 9. Box chart showing daily energy delivered by the AHS of SHS-PCM and SHS-without PCM, along with the daily heat consumption of the building.

Figure 10 shows the proportions of heat supplied to SHS-PCM and SHS-without PCM by three heat sources (AHS, storage tank, and FSTCs direct heating) during the entire heating season water storage tank. As shown in the bar chart, for SHS-without PCM, the AHS provides $76 \%$ of the heat, while the water tank without PCM and the FSTCs provide $14 \%$ and $10 \%$ of the heat, respectively. Thus, the energy saving rate is $24 \%$. For SHS-PCM, the AHS provides $42 \%$ of the heat, while the PCM storage tank and the FSTCs provide 5\% and 53\% of the heat, respectively. Thus, the energy saving rate is $58 \%$.

It can be seen from Figures 9 and 10 that SHS-PCM saves 34\% more energy than SHS-without PCM. In addition, after the PCM storage tank is adopted, the volume of the water tank is reduced to $1 / 5$ of an ordinary water tank. The primary reason is that more solar energy is supplied directly from the FSTCs to the indoor terminals and the PCM storage tank makes a relatively low contribution to the heating of the terminal. It is necessary to optimize the selection of the PCM storage tank. 


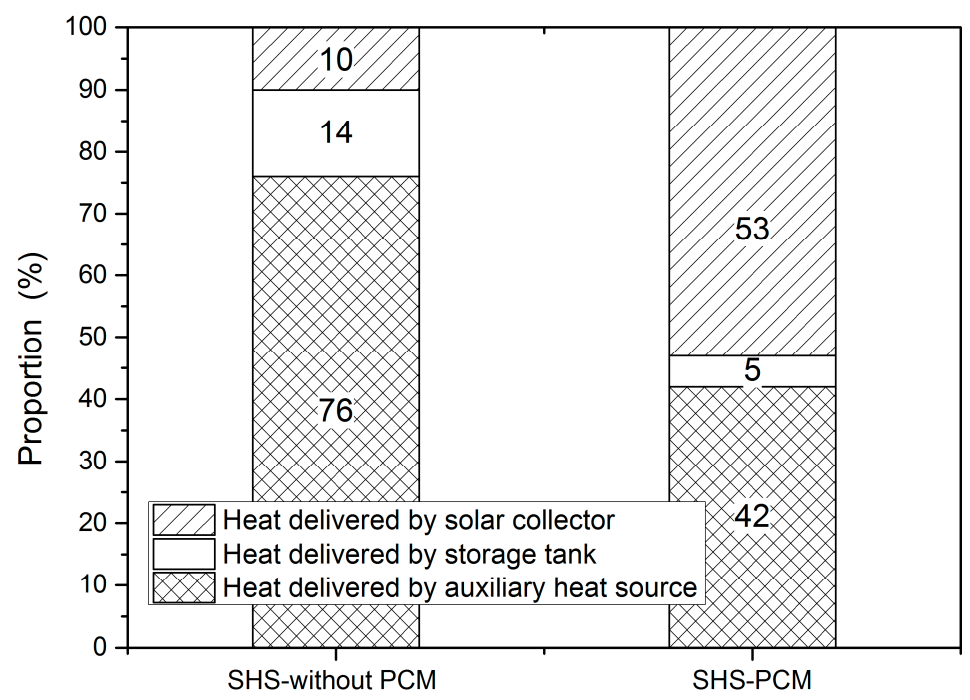

Figure 10. Heat supply proportions of AHS, water storage tank, and FSTCs direct heating for SHS-PCM and SHS-without PCM.

\subsubsection{Operating Conditions Comparison with Different Sizes of PCM Storage Tanks}

In order to take advantage of the heating effect of the PCM storage tank, the operation condition of each heating system is analyzed during the full heating season, under the condition that only the PCM storage tank size and heat capacity are changed while the building characteristics and indoor and outdoor parameters are constant.

The statistics on the daily storage capacity of the public building are given in Table 4 .

Table 4. Different selection parameters of PCM storage tank.

\begin{tabular}{ccccccc}
\hline $\begin{array}{c}\text { Daily Heat } \\
\text { Storage/GJ }\end{array}$ & Days/Day & $\begin{array}{c}\text { Percentage } \\
\text { of Days/\% }\end{array}$ & Plate Volume/m & $\begin{array}{c}\text { Plate } \\
\text { Number/Block }\end{array}$ & $\begin{array}{c}\text { Tank } \\
\text { Volume/m }\end{array}$ & $\begin{array}{c}\text { Actual Heat } \\
\text { Storage/GJ }\end{array}$ \\
\hline 0 & 5 & 4 & - & - & - & - \\
0.5 & 31 & 23 & - & - & - & - \\
0.63 & 47 & 35 & $3 \times 2.5 \times 0.08$ & 6 & $3 \times 2.5 \times 0.8$ & 0.63 \\
1 & 72 & 53 & $3 \times 2.5 \times 0.08$ & 10 & $3 \times 2.5 \times 1.3$ & 1.04 \\
1.5 & 97 & 71 & $3 \times 2.5 \times 0.08$ & 14 & $3 \times 2.5 \times 2$ & 1.46 \\
2 & 114 & 84 & $3 \times 2.5 \times 0.08$ & 19 & $3 \times 2.5 \times 2.5$ & 1.98 \\
2.5 & 128 & 94 & $3 \times 2.5 \times 0.08$ & 24 & $3 \times 2.5 \times 3.2$ & 2.5 \\
3 & 133 & 98 & - & - & - & - \\
3.26 & 136 & 100 & $3 \times 2.5 \times 0.08$ & 26 & $3 \times 3 \times 2.5$ & 3.26 \\
\hline
\end{tabular}

The daily heat storage is calculated in 0.5 GJ intervals in Table 4 , and the percentage of days in the heat storage relative to the total number of days in the heating season is obtained. It can be seen that the proportion of days of heat storage below $1 \mathrm{GJ}$ is $53 \%$, the proportion of days under $2 \mathrm{GJ}$ is $84 \%$, and the proportion of days under $2.5 \mathrm{GJ}$ is $94 \%$, while the daily heat storage rate of $0.63 \mathrm{GJ}$ is $35 \%$.

In accordance with the "Technical code for solar heating system (GB 50495-2009)" for the Lhasa area, which specifies a $150 \mathrm{~L}$ water storage tank with a square meter collector, a large part of the solar radiation is still not being stored. Therefore, PCM storage tanks with heat storage capacities of $0.63 \mathrm{GJ}$, 1.04 GJ, 1.46 GJ, 1.98 GJ, 2.5 GJ, and 3.26 GJ are utilized in the tests described in this section while other system conditions are constant; i.e., the same building and fan coil terminal were used, and the supply and return water temperatures were $45^{\circ} \mathrm{C}$ and $40^{\circ} \mathrm{C}$, respectively. The operating conditions of the building were analyzed for the whole heating season to determine which PCM storage tank system offers the best energy saving capability. 
Figure 11 shows the daily energy delivered by the AHS of SHS-PCM during the entire heating season, using PCM storage tanks with different heat storage capacities. It can be seen from the data and box chart that the average daily heat supplied by AHS has not obviously decreased or increased, although the heat storage capacity of the PCM storage tank increases from $0.63 \mathrm{GJ}$ to $3.26 \mathrm{GJ}$. For the six different heat storage capacities, the heat quantities supplied by AHS are $2202 \mathrm{MJ}, 2083 \mathrm{MJ}, 2020 \mathrm{MJ}$, 2023 MJ, 2050 MJ, and 2072 MJ, respectively.

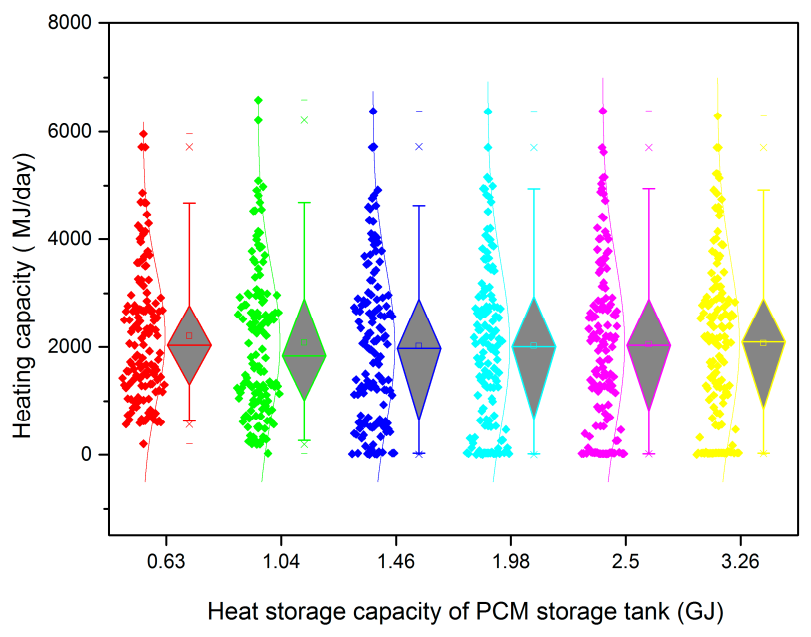

Figure 11. Box chart of daily energy delivered by AHS of SHS-PCM using different capacities of PCM storage tanks.

Figure 12 shows the proportion of heat supplied to SHS-PCM by three heat sources (AHS, PCM storage tank, and FSTCs direct heating) over the entire heating season water storage tank, using PCM storage tanks with different heat storage capacities. The heat storage capacity of the PCM storage tank increases from $0.63 \mathrm{GJ}$ to $3.26 \mathrm{GJ}$; for the six successive capacities, the percentages of heat supplied by AHS are $42 \%, 40 \%, 39 \%, 39 \%, 39 \%$, and $40 \%$, respectively.

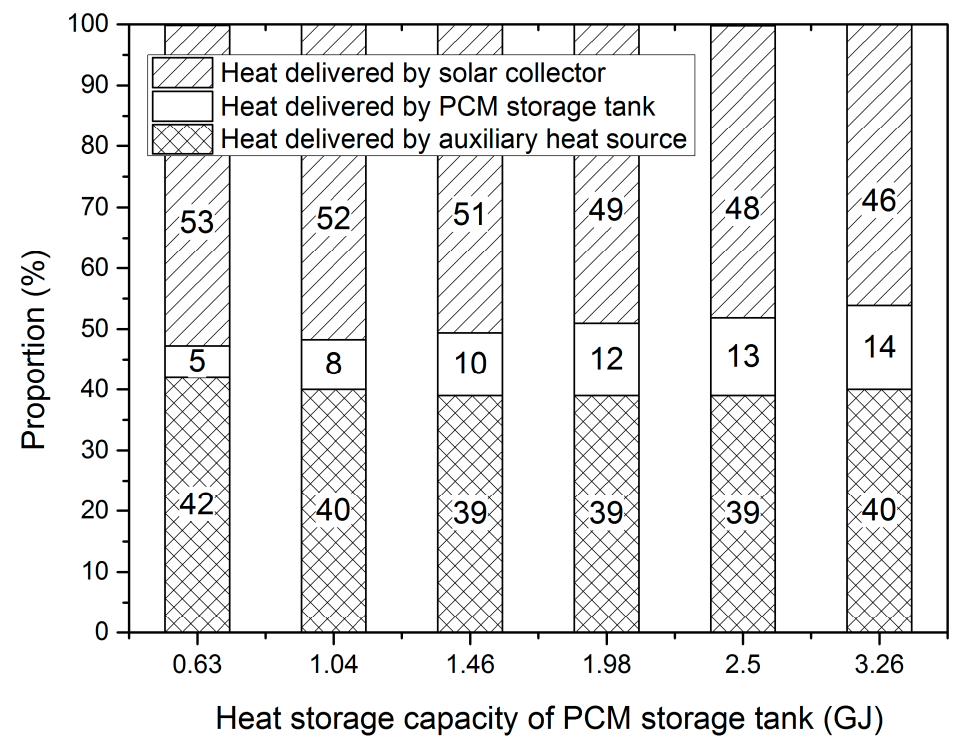

Figure 12. Proportions of heat supplied by AHS, PCM storage tank, and FSTCs direct heating, with different capacities of PCM storage tanks. 
The changes in the heat storage capacity of the PCM storage tank did not have a significant influence on the utilization of solar energy. The direct heat from the FSTCs played a greater role than the PCM storage tank in terms of heating proportions. Their respective proportions for the six successive PCM storage tank capacities were $53 \%, 52 \%, 51 \%, 49 \%, 48 \%, 46 \%$, and $5 \%, 8 \%, 10 \%, 12 \%$, $13 \%, 14 \%$. With the increase in heat storage capacity, the proportion of heat supplied by the PCM storage tank gradually increases.

According to the above analysis, with the increase in heat storage, the heat supplied by AHS does not decrease correspondingly; it decreases at first, rebalances, and then rises. The main reason for this situation is that the smaller the heat storage capacity of the PCM tank, the easier the heated water will reach the required heating temperature so that the indoor heating can be carried out as soon as possible. The larger the heat storage capacity of the PCM tank, the longer period of time the PCM tank will operate although the PCM tank is initially starts slowly. As the solar radiation and indoor load at any time in the change, so sometimes the smaller PCM tank can replace the AHS rapidly, and sometimes the larger PCM tank can delay the operation of AHS. From the simulation results of the whole heating season, the heat supplied by the auxiliary source shows little change when the heat storage capacity of the tank is 1.46 2.5 GJ, and the energy saving effect of the system is obvious when the heat storage capacity is less than 1.46 GJ. Therefore, it is considered that an SHS-PCM with a $1.46 \mathrm{GJ}$ heat storage capacity is the best choice; moreover, it is suggested that the design selection parameters for the PCM storage tank should specify a daily heat storage capacity that satisfies $70 \sim 80 \%$ of the entire heating season.

\subsection{Operating Conditions of Different Terminal Forms}

The system design parameters of five different operating conditions under different terminal forms and different supply and return water temperatures are listed in Table 2. A PCM storage tank with a capacity of $1.46 \mathrm{GJ}$ was chosen to analyze the operation conditions of each heating system during the heating season.

Figure 13 shows the daily energy delivered by the AHS of SHS-PCM with different terminal forms and different supply/return water temperatures during the entire heating season. The data and box chart show that the selected terminal forms and the supply/return water temperatures are as follows: floor radiation $\left(40 / 35^{\circ} \mathrm{C}\right)$, floor radiation $\left(40 / 30^{\circ} \mathrm{C}\right)$, fan coil $\left(45 / 40^{\circ} \mathrm{C}\right)$, fan coil $\left(45 / 35^{\circ} \mathrm{C}\right)$, and radiator $\left(70 / 45^{\circ} \mathrm{C}\right)$. The corresponding average daily heat supplied by the AHS is $1898 \mathrm{MJ} /$ day, $2824 \mathrm{MJ} /$ day, $1988 \mathrm{MJ} /$ day, $2660 \mathrm{MJ} /$ day, and $2939 \mathrm{MJ} /$ day. Among these, floor radiation $\left(40 / 35^{\circ} \mathrm{C}\right)$ has the minimum AHS requirement while radiator $\left(70 / 45^{\circ} \mathrm{C}\right)$ has the maximum AHS requirement.

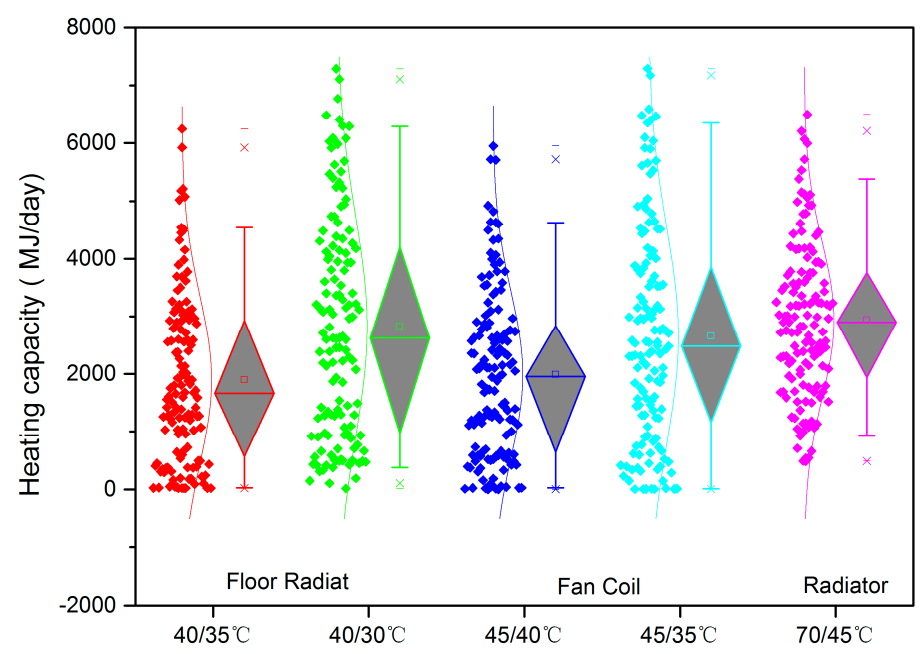

Figure 13. Box chart of daily energy delivered by AHS of SHS-PCM with different terminal forms and heating temperatures. 
Figure 14 shows the proportion of heat supplied to SHS-PCM by three heat sources (AHS, PCM storage tank, and FSTCs direct heating) over the entire heating season, water storage tank with different terminal forms and heating temperatures. The selected terminal forms and the supply/return water temperatures are as follows: floor radiation $\left(40 / 35^{\circ} \mathrm{C}\right)$, floor radiation $\left(40 / 30{ }^{\circ} \mathrm{C}\right)$, fan coil $\left(45 / 40{ }^{\circ} \mathrm{C}\right)$, fan coil $\left(45 / 35{ }^{\circ} \mathrm{C}\right)$, and radiator $\left(70 / 45^{\circ} \mathrm{C}\right)$. The corresponding proportions of heat supplied by AHS are $14 \%, 11 \%, 10 \%, 10 \%$, and $4 \%$. The proportions of heat supplied by FSTCs direct heating are $50 \%, 34 \%, 52 \%, 39 \%$, and $39 \%$. The above statistics show that the highest proportion of solar energy utilization is in the system with floor radiation $\left(40 / 35^{\circ} \mathrm{C}\right)$, in which the utilization rate of solar energy can reach $64 \%$. This is mainly because the lower the supply heating temperature, the easier the PCM tank and the FSTCs direct heating are satisfied the requirements, thereby reducing the operation time of AHS.

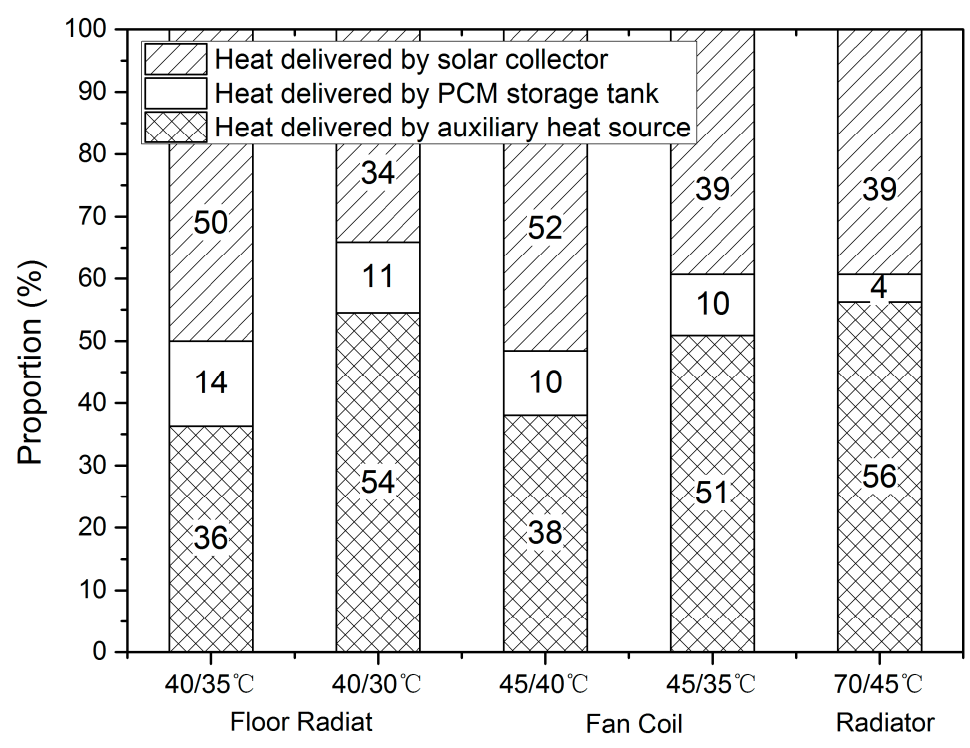

Figure 14. Heat supply proportions of AHS, PCM storage tank, and FSTCs direct heating, with different terminal forms and heating temperatures.

As shown in Figures 13 and 14 for different terminal forms and different temperatures of supply/return water, the optimal operational conditions and energy saving capability for SHS-PCM over the entire heating season are provided by floor radiation $\left(40 / 35^{\circ} \mathrm{C}\right)$, followed by fan coil $\left(45 / 40{ }^{\circ} \mathrm{C}\right)$, fan coil $\left(45 / 35^{\circ} \mathrm{C}\right)$, floor radiation $\left(40 / 30^{\circ} \mathrm{C}\right)$, and radiator $\left(70 / 45^{\circ} \mathrm{C}\right)$.

\section{Conclusions}

An entire heating season (November-March) is selected as the research period on the basis of numerical models of the SHS-PCM. In addition, taking a public building in Lhasa as the object, the heating conditions, contribution rate of solar energy, and overall energy-saving capability provided by the heating system are analyzed under different PCM storage tanks and different terminal forms.

Through a comparative analysis of several system conditions, the following conclusions were obtained:

(1) The operating conditions of SHS-without PCM and SHS-PCM were analyzed in order to explore the contribution rate of ordinary water tanks and PCM storage tanks in a solar heating system. The results show that an SHS-PCM system saves 34\% more energy than an ordinary water tank heating system. In addition, after the PCM storage tank is adopted, the water tank volume is reduced to $1 / 5$ the size of the ordinary water tank. Because more solar energy is supplied directly from the FSTCs to the indoor terminals and owing to the PCM storage tank's relatively low 
contribution to the heating of the terminal, it is necessary to optimize the selection of the PCM storage tank.

(2) Operating conditions with different sizes of PCM storage tanks were compared in order to optimize the selection of the PCM storage tank. The results show that with the increase in heat storage, the heat supply of AHS does not decrease correspondingly; it decreases first, rebalances, and then rises. It is suggested that the design selection parameters of the PCM storage tank should specify a daily heat storage capacity that satisfies $70 \sim 80 \%$ of the entire heating season.

(3) Operating conditions observed with different terminal forms and different temperatures of supply and return water were compared in order to find the terminal form that best matches the PCM storage tank. The results show that for different terminal forms and different designed temperatures of supply/return water, the best operational conditions and energy saving capability for SHS-PCM over an entire heating season are provided by floor radiation $\left(40 / 35^{\circ} \mathrm{C}\right)$, followed by fan coil $\left(45 / 40^{\circ} \mathrm{C}\right)$, fan coil $\left(45 / 35^{\circ} \mathrm{C}\right)$, floor radiation $\left(40 / 30^{\circ} \mathrm{C}\right)$, and radiator $\left(70 / 45^{\circ} \mathrm{C}\right)$.

The analyses above show obviously energy-saving effect of the SHS-PCM. However, the mathematical models of the components on the heat sources side have been established such as PSTCs, PCM tank, AHSs and plate heat exchanger, but the terminal forms has just calculated the hourly heat load of the whole heating season but not established the mathematical model. In addition, ignoring the heat dissipation of the pipelines will also lead to the deviation. More meaningful advice is that PCMs with high heat transfer coefficient will lengthen the operation of the PCM tank and strengthen the energy-saving effect of the SHS-PCM.

Acknowledgments: We acknowledge funding from the Program of the Youth Science and Technology Innovation Team of Sichuan Province of Building Environment and Energy Efficiency (No: 2015TD0015) and Key Research and Development Program of Sichuan Province (No: 2017GZ0389).

Author Contributions: Juan Zhao and Yanping Yuan conceived and designed the experiments; Juan Zhao performed the experiments; Yasheng Ji and Juan Zhao analyzed the data; Jun Lu contributed materials and analysis tools; Juan Zhao, Yasheng Ji, Yanping Yuan and Zhaoli Zhang wrote the paper.

Conflicts of Interest: The authors declare no conflict of interest.

\section{Nomenclature}

A Area, $\mathrm{m}^{2}$

$H_{m} \quad$ Enthalpy of PCM, $\mathrm{kJ} / \mathrm{kg} \quad p$

I Radiant intensity, $\mathrm{W} / \mathrm{m}^{2}$

$K \quad$ Heat transfer coefficient, $\mathrm{W} /\left(\mathrm{m}^{2} \cdot{ }^{\circ} \mathrm{C}\right) \quad T$

$L \quad$ Length of PCM plate, $\mathrm{m} \quad \Delta t$

$l$ Length, $\mathrm{m} \quad V$

$m$ Mass flow rate, $\mathrm{kg} / \mathrm{s} \quad x$

$M \quad$ Quality, $\mathrm{kg} \quad y$

$C_{p} \quad$ Specific heat at constant pressure, $\mathrm{J} /(\mathrm{kg} \cdot \mathrm{K})$

$h \quad$ Coefficient of convective heat transfer, $\mathrm{W} /\left(\mathrm{m}^{2} \cdot \mathrm{K}\right)$

\section{Greek symbols}

$\rho \quad$ Density, $\mathrm{kg} / \mathrm{m}$

$\eta \quad$ Efficiency

$\beta \quad$ Heat resistance of dimensionless number

\section{Subscripts}

C Solar thermal collector

e Load

ev Environment

$f \quad$ Fluid

$g \quad$ Heat collection medium

$h \quad$ Plate heat exchanger

hp Heat storage tank
Number

Wetted perimeter, $\mathrm{m}$

Quantity of heat, J

Temperature, ${ }^{\circ} \mathrm{C}$

Temperature difference, ${ }^{\circ} \mathrm{C}$

Volume, $\mathrm{m}^{3}$

$\mathrm{x}$-coordinate, $\mathrm{m}$

The height of the phase transition interface

Thickness, $\mathrm{m}$

Volume fraction

Maximum

Internal energy

Outlet

Wall of encapsulated version

PCM plate

Thermal energy

Auxiliary heat source 
I Radiation

in Inlet

$l \quad$ Luminous energy

$m \quad$ PCM

Abbreviations

AHS Auxiliary Heat Source

FSTC Flat-plate Solar Thermal Collector

HTF Heat transfer fluid

IHS Indoor heating system

LHS Latent heat storage

LTES Latent thermal energy storage s $\quad$ Solid

us Useful energy

W Water

V Volume

PCM Phase change material

PCTSS Phase change thermal storage system

SCS solar collection system

SDHW Solar domestic hot water

SHS-PCM Solar heating system with PCM storage tank

TES Thermal energy storage

\section{References}

1. Zhou, Z.H.; Zhang, Z.M.; Zuo, J.; Huang, K.; Zhang, L.Y. Phase change materials for solar thermal energy storage in residential buildings in cold climate. Renew. Sustain. Energy Rev. 2015, 48, 692-703. [CrossRef]

2. Ouyang, L.P.; Sun, L.L.; Yuan, Y.P.; Cao, X.L.; Xiang, B. Optimum connection modes for photovoltaic thermal collectors in different radiation zones of China. Appl. Therm. Eng. 2017, 122, 661-672. [CrossRef]

3. Yuan, Y.P.; Ouyang, L.P.; Sun, L.L.; Cao, X.L.; Xiang, B.; Zhang, X.X. Effect of connection mode and mass flux on the energy output of a PVT hot water system. Sol. Energy 2017, 158, 285-294. [CrossRef]

4. Sun, L.L.; Li, M.; Yuan, Y.P.; Cao, X.L.; Lei, B.; Yu, N.Y. Effect of tilt angle and connection mode of PVT modules on the energy efficiency of a hot water system for high-rise residential buildings. Renew. Energy 2016, 93, 291-301. [CrossRef]

5. Yuan, Y.P.; Gao, X.K.; Wu, H.W.; Zhang, Z.J.; Cao, X.L.; Sun, L.L.; Yu, N.Y. Coupled cooling method and application of latent heat thermal energy storage combined with pre-cooling of envelope: Method and model development. Energy 2017, 119, 817-833. [CrossRef]

6. Yuan, Y.P.; Zhang, N.; Li, T.Y.; Cao, X.L.; Long, W.Y. Thermal performance enhancement of palmitic-stearic acid by adding graphene nanoplatelets and expanded graphite for thermal energy storage: A comparative study. Energy 2016, 97, 488-497. [CrossRef]

7. Kenisarin, M.; Mahkamov, K. Solar energy storage using phase change materials. Renew. Sustain. Energy Rev. 2007, 11, 1913-1965. [CrossRef]

8. Wang, Z.Y.; Qiu, F.; Yang, W.S.; Zhao, X.D. Applications of solar water heating system with phase change material. Renew. Sustain. Energy Rev. 2015, 52, 645-652. [CrossRef]

9. Liu, M.; Belusko, M.; Steven Tay, N.H.; Bruno, F. Impact of the heat transfer fluid in a flat plate phase change thermal storage unit for concentrated solar tower plants. Sol. Energy 2014, 101, 220-231. [CrossRef]

10. Xiang, B.; Cao, X.; Yuan, Y.; Sun, L.; Wu, H.; Haghighat, F. A novel hybrid energy system combined with solar-road and soil-regenerator: Dynamic model and operational performance. Energy Convers. Manag. 2018, 156, 376-387. [CrossRef]

11. Saxena, A.; Varun; El-Sebaii, A.A. A thermodynamic review of solar air heaters. Renew. Sustain. Energy Rev. 2015, 43, 863-890. [CrossRef]

12. Bouadila, S.; Fteti, M.; Oueslati, M.M.; Guizani, A.; Farhat, A. Enhancement of latent heat storage in a rectangular cavity: Solar water heater case study. Energy Convers. Manag. 2014, 78, 904-912. [CrossRef]

13. Mahfuz, M.H.; Anisur, M.R.; Kibria, M.A.; Saidur, R.; Metselaar, I.H.S.C. Performance investigation of thermal energy storage system with Phase Change Material (PCM) for solar water heating application. Int. Commun. Heat Mass Transf. 2014, 57, 132-139. [CrossRef]

14. Agyenim, F.; Hewitt, N.; Eames, P.; Smyth, M. A review of materials, heat transfer and phase change problem formulation for latent heat thermal energy storage systems (LHTESS). Renew. Sustain. Energy Rev. 2010, 14, 615-628. [CrossRef]

15. Xu, H.X.; Sze, J.Y.; Romagnoli, A.; Py, X. Selection of Phase Change Material for Thermal Energy Storage in Solar Air Conditioning Systems. Energy Procedia 2017, 105, 4281-4288. [CrossRef]

16. Zheng, L.; Zhang, W.; Liang, F. A review about phase change material cold storage system applied to solar-powered air-conditioning system. Adv. Mech. Eng. 2017, 9, 1-20. [CrossRef] 
17. Cao, X.; Yuan, Y.; Xiang, B.; Sun, L.; Zhang, X. Numerical investigation on optimal number of longitudinal fins in horizontal annular phase change unit at different wall temperatures. Energy Build. 2018, 158, $384-392$. [CrossRef]

18. Belmonte, J.F.; Eguía, P.; Molina, A.E.; Almendros-Ibáñez, J.A.; Salgado, R. A simplified method for modeling the thermal performance of storage tanks containing PCMs. Appl. Therm. Eng. 2016, 95, 394-410. [CrossRef]

19. Zhang, S.M.; Zhang, L.Y.; Yang, X.H.; Yu, X.L.; Duan, F.; Jin, L.W.; Meng, X.Z. Experimental Investigation of a Spiral Tube Embedded Latent Thermal Energy Storage Tank Using Paraffin as PCM. Energy Procedia 2017, 105, 4543-4548. [CrossRef]

20. Meng, Z.N.; Zhang, P. Experimental and numerical investigation of a tube-in-tank latent thermal energy storage unit using composite PCM. Appl. Energy 2017, 190, 524-539. [CrossRef]

21. Lu, S.L.; Zhang, T.S.; Chen, Y.F. Study on the Performance of Heat Storage and Heat Release of Water Storage Tank with PCMs. Energy Build. 2017, 158, 1770-1780. [CrossRef]

22. Senthil Kumar, G.; Nagarajan, D.; Chidambaram, L.A.; Kumaresan, V.; Ding, Y.; Velraj, R. Role of PCM addition on stratification behaviour in a thermal storage tank-An experimental study. Energy 2016, 115, 1168-1178. [CrossRef]

23. Talmatsky, E.; Kribus, A. PCM storage for solar DHW: An unfulfilled promise? Sol. Energy 2008, 82, 861-869. [CrossRef]

24. Najafian, A.; Haghighat, F.; Moreau, A. Integration of PCM in domestic hot water tanks: Optimization for shifting peak demand. Energy Build. 2015, 106, 59-64. [CrossRef]

25. Haillot, D.; Franquet, E.; Gibout, S.; Bedecarrats, J.P. Optimization of solar DHW system including PCM media. Appl. Energy 2013, 109, 470-475. [CrossRef]

26. Padovan, R.; Manzan, M. Genetic optimization of a PCM enhanced storage tank for Solar Domestic Hot Water Systems. Sol. Energy 2014, 103, 563-573. [CrossRef]

27. Kaygusuz, K.; Ayhan, T. Experimental and theoretical investigation of combined solar heat pump system for residential heating. Energy Convers. Manag. 1999, 40, 1377-1396. [CrossRef]

28. Zhang, Y.; Chen, C.; Jiao, H.; Wang, W.J.; Shao, Z.Y.; Qi, D.W.; Wang, R. Thermal Performance of New Hybrid Solar Energy-phase Change Storage-floor Radiant Heating System. Procedia Eng. 2016, 146, 89-99. [CrossRef]

29. Zhao, J.; Ji, Y.; Yuan, Y.; Zhang, Z.; Lu, J. Seven Operation Modes and Simulation Models of Solar Heating System with PCM Storage Tank. Energies 2017, 10. [CrossRef]

30. Ministry of Housing and Urban-Rural Development of the People's Republic of China. Design Code for Heating Ventilation and Air Conditioning of Civil Buildings; China Architecture \& Building Press: Beijing, China, 2012; GB 50736-2012.

31. Ministry of Housing and Urban-Rural Development of the People's Republic of China. Technical Code for Solar Heating System; China Architecture \& Building Press: Beijing, China, 2009; GB 50495-2009. 